This is an author produced version of a paper published in Sexualities. This paper has been peer-reviewed but does not include the final publisher proof-corrections or journal pagination.

Citation for the published paper:

Carlström, Charlotta. (2019). BDSM - the antithesis of good Swedish sex?. Sexualities, vol. 22, issue 7-8, p. null

URL: https://doi.org/10.1177/1363460718769648

Publisher: Sage

This document has been downloaded from MUEP (https://muep.mah.se) / DIVA (https://mau.diva-portal.org). 


\title{
BDSM - the antithesis of good Swedish sex?
}

Sexualities

\author{
Charlotta Carlström
}

2018

Malmö University, Sweden

DOI $10.1177 / 1363460718769648$

\begin{abstract}
In this article, based on ethnographic fieldwork, and interviews with 29 self-defined BDSM practitioners, I explore the incorporation process of BDSM (Bondage and Discipline, Dominance and Submission, Sadism and Masochism) in Swedish society. I argue that the so-called 'good sexuality' described by Gayle Rubin (2011) and Don Kulick (2005) is still alive as a normative principle in this context. Drawing on Foucault's concept 'biopower' (1976), I show that to gain acceptance and to fit into a society characterized by 'good sexuality', BDSM has to be normalized. This normalization process is closely connected to a middle-class hegemony and results in limitations that in various ways affect the practitioners, as well as impacting the transgressive core of BDSM.
\end{abstract}

Keywords

BDSM, biopower, normalization, sexuality, Swedish society 


\section{Introduction}

In this article, based on ethnographic fieldwork and interviews with 29 selfdefined BDSM practitioners, I explore the incorporation process of BDSM (Bondage and Discipline, Dominance and Submission, Sadism and Masochism) in Swedish society. Sweden is often talked of as a sex positive and sex liberal nation. For example, in 1955, Sweden became the first nation in the world to introduce mandatory sex education in schools. Films produced in the 1950s, such as Ingmar Bergman's The Summer with Monika (1953) and Arne Mattsson's One Summer of Happiness (1951), helped to launch the concept of 'Swedish sin' on the international arena, while in the 1960s, a number of public figures demanded abortion and free porn (Lennerhed, 1994). It was also during this period that the psychiatrist Hans Ullerstam (1964) wrote Sexual Minorities, a work which had a major impact both in Sweden and internationally. In this groundbreaking book, Ullerstam pursues the argument that society should facilitate for sexual minorities to achieve pleasure. Today, it appears that several kinds of sexual expression that differ from the heteronormative norm have in fact achieved acceptance in Swedish society, to varying degrees. It is for instance no longer considered important to be married to the person one has sex with, and tolerance for same-sex sexuality and persons belonging to sexual minorities has increased.

Against this background, it may seem surprising that very few studies in Sweden deal with different sexual orientations and variations, such as polyamory, group sex, fetishism and BDSM. According to Rubin (2011), modern western societies appraise sex acts according to a hierarchical system of sexual value. Marital, reproductive heterosexuals are at the top of the erotic pyramid. Consequently, they 'are rewarded with certified mental health, respectability, legality, social and physical mobility, institutional support, and material benefits' (2011: 149). The most despised sexual castes include, for example, transsexuals, fetishists, sadomasochists and sex workers. The aim of the present article is therefore to focus on BDSM as one of the areas which is attributed lower value, and to explore impacts of such values on the incorporation process of BDSM in Swedish society. Drawing on Foucault's (1976, 1997a, 1997b) concept of 'biopower', as well as Bourdieu's (1989) theorization of middle-class cultural capital, the questions that will be discussed are to what extent BDSM has become mainstream and accepted in Swedish society, and if so, at what cost acceptance has come.

\section{Method}

Ethnographic fieldwork was conducted in 2012 and 2013 within different BDSM communities in Sweden. The fieldwork included interviews, observations and participation in meetings, workshops, pub evenings and club ventures. In total, 29 persons defining themselves as practitioners 
were interviewed. I searched for participants in different ways. One point of access was becoming a member of Darkside.se (the largest Swedish BDSM community on the internet, with approximately 180,000 members), where I advertised my research project. I also advertised in a sex shop, and contacted non-profit organizations working with sexual health and rights, such as the Swedish Association for Sexuality Education (RFSU) and the Swedish Federation for Lesbian, Gay, Bisexual, Transgender and Queer Rights (RFSL). A few informants served as gatekeepers (May, 1993), by helping me gain access to different meetings and clubs and conveying contact information to other people. This method - often referred to as the 'snowball' method - can help researchers find and recruit participants that may otherwise be hard to reach. However, the self-selectivity in this kind of sampling is not unproblematic. Initial subjects tend to nominate people that they know well and it is therefore highly possible that the participants share the same traits and characteristics. Advertising in different places and in different cities was a way to avoid sampling bias. Finally, while I made efforts to keep the group of informants as representative as possible, it is not a simple random sample of BDSM practitioners in Sweden, since it consists of people who were interested in participating in this research project. It is import- ant to keep this in mind, particularly when comparing with empirical data in some of the other studies referred to, and where other sampling methods, categories and ways to analyse the data may have been used. Both background and analysis draw from a wide range of modes of social research, which also has implications for the conclusions.

The informants were aged between 20 and 60. They lived in cities, smallertowns and in rural areas in different parts of Sweden. There were 14 who identified them- selves as women, 14 as men, and 1 as transgender; 9 identified as dominant and/or sadists, 13 as submissive and/or masochists, and 7 as switches. Of all the inform- ants, 20 had a university education.

My contact with informants varied: some I met only once for an interview, others several times in different contexts for repeated interviews. Interviews ranged from about one hour to four hours. I conducted every interview alone and did all of the transcribing and analysis myself. The interviews were frequently characterized by a reflective ambivalence, where the informants brought up topics and areas that they had clearly thought and reasoned about for some time, with thoughts that were often complex and not always easy to comprehend. Many of the informants pointed out that it is important to be attentive and communicative about the complexity of the practices. Questions and fear of what research on BDSM would result in were present in my field studies. In one field note I wrote: 
At the end of the meeting, I asked if I could attend the meetings regularly. One person said: 'There is a power imbalance in that we are so open but we know nothing about you. We are probably several who have wondered why you have this interest to do research about BDSM'. Another guy said, half jokingly half seriously: 'Your purpose might be to prohibit BDSM'. I answered: 'No, I would rather try to give a balanced picture of what BDSM means, I think that there are many misunderstandings about the BDSM community'.

The field note is an example of how I often was 'tested' to see if I was trustworthy by the informants. It can also serve as an example of how the study raised questions concerning power in relation to the normalization process of BDSM in Swedish society. I repeatedly had to explain the purpose of the study; that the aim was not to work for the prohibition of BDSM, but rather to explore the practitioners' own experiences. Throughout the entire project, ethical considerations played a central role. The names of all informants have been anonymized. Prior to interviews, I provided written information to the informant where I described the purpose of the study: that it is voluntary to participate, that the informant at any time is allowed to withdraw her or his participation, and that personal data are treated confidentially. None of the informants in this study withdrew her or his involvement. The project follows the Research Council's ethical guidelines (Codex, 2012) and was reviewed by the Regional Ethical Review Board. ${ }^{1}$

\section{What is BDSM?}

BDSM has been described in various arenas: from medicine and research to political activism, literature, film and media. There are few BDSM studies produced outside the western world and most of the existing research comes from the USA and England (see for example Barker, 2013; Beckmann, 2009; Newmahr, 2011; Weinberg, 2006; Weiss, 2011). From being dominated by clinical and therapeutic perspectives, research has increasingly been conducted with a sociological and psychological orientation, in which BDSM is mainly seen as sexual behaviour (see for example Langdridge and Barker, 2007; Levitt et al., 1994; Plante, 2006; Sandnabba et al., 1999; Taylor and Ussher, 2001; Weinberg, 2006). From this perspective, the practice is understood as culturally produced and dependent on asocial context. Until the year 2009, sadomasochism was classified as a psychiatric diagnosis, according to the Swedish version of the diagnostic system ICD-10. 
The umbrella term BDSM is used to describe a variety of (sexual) behaviours involving an implicit or explicit erotic power exchange. It is uncommon that practitioners are interested in every practice the concept accommodates. Rather, one talks about different preferences, so-called 'kinks'. For some practitioners, the roles are limited to sexual role-play, while for others the roles are adopted 24/7 (Weinberg, 2006). The BDSM communities are seen as very important, since they add meaning, as well as offering security and a sense of belonging to the practitioners. The scene functions as safe space, allowing practitioners to play with power and taboos in a way that would be impossible outside the scene (Bauer, 2014; Newmahr, 2011). In line with the findings of Newmahr (2011) and Beckmann (2009), the informants of this study describe how BDSM is built on desire, fantasies, excitement, bodily sensations, thoughts and feelings, where the practice transgresses and at times transcends taboos, boundaries, prohibitions and social norms. The practice also concerns fundamental existential needs, such as safety, belonging and meaning, which individuals in contemporary society may find difficult to satisfy. Many practitioners express that BDSM fills an existential void (Ambler et al., 2016; Beckmann, 2009). The social contexts relating to BDSM in this study included clubs, private parties, pub evenings and workshops; places where practitioners meet to socialize, learn and practice BDSM. In the communities investigated here, there was a constant influx of new people. The informants describe welcoming attitudes toward newcomers and a learning process in which they assimilate techniques, rules and norms of the community, as well as a social responsibility where the participants are taught a moral and ethical behaviour (see also Beckmann, 2009). Several studies indicate that by highlighting the significant role of consent in the practices, practitioners can position themselves against the discourse of BDSM as violence (Barker, 2013; Bauer, 2014; Carlström, 2017; Cruz, 2016).

BDSM is a hot topic in media and popular culture. Since Erika Leonard James's bestselling book 50 Shades of Grey, countless talk shows, films and articles in newspapers and magazines testify to the current interest in BDSM. The recent surge in attention is interesting, considering that just a few years ago, BDSM was a phenomenon that many Swedes barely knew existed. However, the media images in popular culture often consist of stereotypical depictions, coloured by sensationalism and exaggeration, and where practitioners are rarely heard (Carlström 2016). For example, Beckmann points out that "the use of "torture", which distinctively excludes any notion of negotiated consent is still considered to be appropriate in describing consensual SM practices' (Beckman, 2009: 126). The mainstream process of BDSM and BDSM in relation to the surrounding society has been investigated in a few studies (Beckmann, 
2001; Taylor and Ussher, 2001; Weinberg and Magill, 1995; Weiss, 2006). Weiss (2011) is critical of the mainstream process of BDSM, arguing that the increased visibility of BDSM fails to challenge the privilege and hegemony of normative sexuality. She sees BDSM as a 'form of social belonging facilitated - even produced - by contemporary US capitalism, especially consumerism and commodity exchange' (Weiss, 2011: 8). Based on this perspective, Weiss discusses BDSM as a social relation, linking individuals, desires and embodiments, to social hierarchies, communities and relations of inequality. Cruz notes that race is marginalized in both scholarly literature and popular media, 'contributing to the impression that it is not something black people do, or should do’ (2016: 10).

\section{Techniques of power}

Foucault's work is usually divided into three phases: archaeological, genealogical, and ethical. The productive character of power appears primarily during the genealogical phase in the works Discipline and Punish (1975) and The History of Sexuality, Volume I (1976). It is also at this time that Foucault develops the notion of biopower. With the term biopower, he describes 'an explosion of numerous and diverse techniques for achieving the subjugations of bodies and the control of populations' (Foucault, 1976: 140). In the lecture series Security, Territory, Population (1977-1978, see Foucault, 1997a) and The Birth of Biopolitics (1978-1979, see Foucault, 1997b), it is not power as a disciplinary function that occupies Foucault, rather he examines biopower as a new technology of power over populations by tracing the history of governmentality. In The Birth of Biopolitics, he traces how the 18thcentury political economy marked the birth of a new governmental rationality, and raises questions of political philosophy and social policy concerning the role and status of neo-liberalism in 20th-century politics. According to Foucault (1976), individuals are under constant surveillance and regulation in ways thatare often subtle and thereby seemingly invisible, leading to normalization and acceptance of such systems of control. Biopower is characterized by bodily disciplining of individuals designed to form an obedient society. The individuals are addressed as rational, autonomous and self-aware agents who are expected to pursue lives that lead to the greatest degree of well-being, and are hence likely to conduct their lives in accordance with authoritative ideas about how to live a safe and healthy life.

Characteristic for biopower is its concern with improving human life, which is particularly expressed through a focus on issues of sexuality, reproduction and other aspects of public health (Foucault, 1976). 
Individuals who do not conduct themselves in accordance with such discourses may be categorized as deviant, pathological, dangerous, risky or unethical. Sexuality plays a crucial role in this context. To classify some sexual behaviours as 'normal' and others as 'deviant', 'pathological' or 'criminal' is a modern form of social regulation, and part of biopower (Bauer, 2014). According to Weiss (2011), understanding sexuality as a form of biopower 'enables us to see how subjects form and work on themselves in relation to social norms of gender, race, and sexuality' (2011: 170).

Biopower is also about systematic control of the population as a whole (for example, by statistics to clarify demographic patterns). Cisney and Morar(2015:5) point to the implications of biopower for sexuality: 'It is something of a nexus in which these two, the health of the body and the health of society, discipline and regulation, fuse into one'. This nexus, the health of the body and the health of society, has been a central set of values in Swedish society for almost a century and was the core of the Swedish 'Folkhemmet' (literally: home of the people). Sometimes referred to as 'the Swedish Middle Way', 'Folkhemmet' was viewed as midway between capitalism and socialism. 'Folkhemmet' is a political concept that played an important role in the Swedish welfare state, particularly in the period 1932-1976 when the Social Democrats were in power and the concept was put into practice (Berggren and Trädgårdh, 2015). In an analysis inspired byFoucault, Johannisson (1997) discusses these historical developments, and describes how a societal fear of 'perversion', 'crime', 'addiction', 'prostitution' and 'normlessness' emerged during the beginning of the 1900s in Sweden. The idea of the threatening body gave legitimacy to forceful measures. The notion of medical, social and racial 'hygiene', combined with moral aspects, was the basis for intense propaganda focusing on the necessary discipline of the body. Johannisson underlines that in this conceptualization: 'the individual was not a free-floating atom, but part of the whole in a cell in the social body, a drop of blood in the state's hot giant organism' (1997: 250). Eating, housing, sexuality, love and parenthood were all to be included in the hygienic programme. The health of the body required the health of the soul, and vice versa. These ideas can be understood as an exercise of power, in the sense given by Foucault, and manifested through the production of knowledge.

Expert knowledge is often taken for granted, and it is easy to rely on someone addressed as an expert. But taking expert knowledge for granted blinds us to the fact that this knowledge also serves as a technology for the monitoring and control of our behaviour. In contrast to expressions of power manifested by the police or the military, this exercise of(bio)power is mostly invisible, and therefore, according to Foucault, also more 
effective and dangerous. As expert power/knowledge pro- duction involves the creation of what we perceive as real and true, it is inevitable that by the same token it functions as a procedure of exclusion and silencing of alternative forms of knowledge and realities. This type of silencing is highlighted by Foucault, who uses the concept 'subjugated knowledges' to describe 'a whole set of knowledges that have been disqualified as inadequate to the task or insufficiently elaborated; naive knowledges, located low down on the hierarchy, beneath the required level of cognition or scientificity' (Foucault, 1980: 82).

Central for biopower are thus the modern western concepts of the 'self' and of 'individual autonomy'. These concepts can in turn be understood as arising out of a western liberal-democratic and liberalhumanist tradition that values a notion of individual liberty, and which is secured by social and political structures in many countries today. There are, however, circumstances that make the Swedish context special. Using the historians Berggren and Trädgård's (2015, 2012) concept 'Swedish theory of love', Kulick and Rydström (2015) discuss in what ways Sweden differs from other countries (and more particularly Denmark). The theory they outline is useful also when it comes to examining BDSM and striving for acceptance. Berggren and Trädgårdh describe Sweden as 'a nation that celebrated the collective but wanted the individual' (2015: 15, my translation), and point to several circumstances that make the Swedish context unique. One of them is that there is a perception in Sweden that love is built on the basis of autonomy rather than interdependence. This notion has taken hold in the modern welfare state institutions, and by investigating the development of Sweden into a welfare state we can gain a better understanding of sexuality and BDSM in Swedish society.

Defenders of the welfare state highlight the benefits of a strong alliance between the state and the individual. However, according to Berggren and Trädgårdh, "modern Sweden is less of a collectivist project that grew out of warm solidarity, and more a fusion of an individualistic view of humanity and a strong egalitarian tradition' (2015: 167, my translation). An individualistic view on family and marriage has been dominant for several centuries. In the 1930s, the laws on 'homosexuality' and abortion were softened, and modernizing the institution of marriage became an explicit goal of state institutions. The 1970s' extensive family policy reforms were more radical and consistent than in most other European countries. These stable foundations of the Swedish welfare state, based on a strong cultural preference for moderation (lagom) also reflect the view of sexuality. The Swedes want an 'all right stamp', and there is a common assumption that Swedes shall be tolerant and understanding (Berggren and Trädgårdh, 2015). 


\section{Good sex in Sweden}

The Swedish position on non-normative sexualities has gradually emerged over the past centuries. Studying the concepts sadism, masochism and sadomasochism, the historian Kim Herburt (2009) examines how sadomasochism was constructed in Swedish reference books and encyclopaedias in the period 1876-2006. He states: 'The sadomasochistic sexuality is constructed as the opposite to the normative good sexuality. Where the good sexuality becomes a tender, loving and egalitarian sexuality without elements of violence and aggression' (Herbert, 2009: 428). Kulick emphasizes that the 'Swedish sin' is everything but perverse and decadent. It is instead what could be qualified as a healthy, clean and normative sexuality:

Sex, Swedish authorities and politicians tell us, is good. The catch is that for sex to be good, it has to be good sex... Sexual practices that diverge from this understanding of 'good sex' - for example, the wordless sexual encounters many gay men enjoy in saunas and parks, or group sex of any kind, or sadomasochistic role-playing set off alarms and raise concerns about exploitation and abuse, concerns that the state feels obliged to address. (Kulick, 2005: 208).

It is more than 10 years since Kulick wrote this, but despite various changes in the knowledge field concerning sexual minorities and BDSM during these years, the observation is still valid. Several informants with experiences from other European BDSM scenes point out that the Swedish context differs from other countries by being more restrained, respectful and moderate. A male sadist said: 'In Sweden, it is more restrained. It has always worked that way. From what I have seen, more respectful. I think sex is generally seen as more embarrassing in Sweden than in Germany and certainly more embarrassing than in Denmark'. A dominant man reflects upon the societal view of BDSM:

BDSM does not belong to the norm of a good Swedish society and culture. You never hear about BDSM in the sex education in school or on the news. Except the horror stories, they get exposure, which is very unfortunate because they will give a very skewed picture of what BDSM means. It is so much more complex and nuanced.

Different approaches to sadomasochism, prostitution and pornography have created ambivalence both at an individual level and in the feminist movement in general. This ambivalence, which was to become the 
hallmark of the feminist movement in the 1970s and 1980s, lives on in Swedish society today. One example is the view of pornography, which in Sweden is commonly and loudly characterized as abusive of and harmful to women (Kulick, 2005). The porn debate, where several influential politicians and organizations demanded zero-tolerance for pornography, is an obvious example of the maintenance of the 'good sexuality' in Swedish society. Kulick and Rydström (2015) point out that Swedish authorities have a tendency to opt for zero-tolerance and absolutist restrictions in response to any issues that become defined as social problems. For example, Sweden was the first country in the world to prohibit the purchase of sexual services. 'The problem is that we live in a sexually hostile society that stigmatizes, shames and blames sex, and consistently oppresses all expressions of human sexuality', the debater and author Carl Johan Rehbinder writes in one of the largest Swedish daily newspapers, Dagens Nyheter (2016). Some debaters and articles describe BDSM as an example of the worst kind of pornography, while there is no debate concerning the demands for zero-tolerance of BDSM. To resist demands for zero-tolerance, a normalization of BDSM would be required. But acceptance and tolerance from the Swedish state can only be achieved by making BDSM fit into the model of the 'good sexuality'.

\section{BDSM's incorporation in Swedish society}

There are several BDSM communities, organizations and sexual political associations, which actively work for and promote the acceptance of BDSM in Swedish society. For instance, both The Swedish Association for Sexuality Education (RFSU), and The Swedish Federation for Lesbian, Gay, Bisexual, Transgender and Queer Rights (RFSL), are partners in dialogue with the government and important lobbying groups. RFSU has played an important role concerning the 'subjugated knowledges' of BDSM in society. The RFSU Stockholm Sex Political BDSM and Fetishism Group was formed in 2006 to focus on issues related to BDSM and fetish practitioners' rights, to work for the removal of sadomasochism as a pathology, and to strengthen previously 'subjugated knowledges' and reduce prejudices about BDSM and fetishism. When asking a female dominant practitioner who is also a member of RFSU about the process of gaining acceptance from RFSU, she said:

There were many old owls who were against BDSM and who thought BDSM was something terrible. It was all about knowledge. Back then there was no knowledge of BDSM in the organization. BDSM was still seen as a paraphilia and a pathological illness. But 
we were several BDSM practitioners within RFSU, demonstrating diversity and the weight of consent. For a long time BDSM was seen as a freak show, which fuelled the myth of the practices as awful. We have worked hard to take away the stigmatization. We wrote a proposal and we signed with our real names, which was a clear indication that we were serious and open with our BDSM preferences. The process of integrating BDSM in RFSL went much more slowly than in RFSU. At first it was a refusal, but then they were asked to form a group that would develop a better proposal and provide more information. And then 2009, the removal of the diagnosis came and at the next RFSL congress, the proposal went through without any discussion. One must anchor the work through knowledge because there is a lot of prejudice and fear.

When RFSU in 2008 accepted to work on issues related to BDSM, a political change process started. One informant in this study was involved in writing a proposal to The National Board of Health and Welfare (Socialstyrelsen) about the removal of sadomasochism as a pathology. She said: 'The process at that time was all about finding a form, to find a way to talk about this. Partly to gain respect, so that people would understand and partly to find a language that was accessible and not too internal'. To find an accessible language and gain respect were thus important ways for the subjugated knowledges of BDSM to become valued and enter mainstream arenas.

Sexuality and sexual expression have been shaped by the dominant discourses in medicine, religion and law which, as Foucault (1976) has expressed it, have 'controlled' bodies through the ages. In this perspective, the purpose of the diagnosis of sadomasochism was a moral method used to control sadomasochistic bodies. Langdridge points out: 'The power of medicine to pathologize has long been recognized, and this is particularly apparent with sadomasochism, where the voice of the participant has been drowned out by the voice of the medical professional' (2011:374). The removal of the diagnosis from the system of classification can in this light be seen as a practice of 'resistance' (Foucault, 1976), and was a way to broaden the norms concerning behaviour that was previously classified as deviant and sick. It is similar to the removal of 'homosexuality' as a criminal act: 'homosexuality' was to be described as innate, biological and pathological. By seeing 'homosexuality' as an orientation that was impossible to choose, a completely different understanding of tolerance and acceptance by society at large could be reached. A similar view can 
be observed among BDSM practitioners today. Weiss explores nonpractitioners' understandings of and responses to the increasingly mainstream representation of BDSM in US media, focusing on the film Secretary (Shainberg, 2002). She states: 'Twenty years ago, SM was (at least in fantasy) something dark and mysterious, unspoken and invisible; today, representations of BDSM are everywhere' (Weiss, 2006: 111). Weiss argues that acceptance and understanding of sexual minorities takes place through two mechanisms: acceptance via normalization, and understanding via de-pathologizing. She continues:

Both mechanisms offer a form of acceptance or understanding, but these forms do not further the cause of sexual freedom. They allow the mainstream audience to flirt with danger and excitement, but ultimately reinforce boundaries between protected and privileged normal sexuality, and policed and pathological not normal sexuality. (Weiss, 2006: 105)

This stance is in line with views on BDSM in Sweden. For example, there is an on- going discussion that BDSM should be categorized as a sexual orientation that was impossible to choose, and thus achieve protection under The Discrimination Act. In 2016, the BDSMF group within RFSU made a proposition (RFSU Stockholm, 2016) to classify BDSM and fetishism as sexual orientations, with the purpose of attaining legal support against discrimination and hate crimes. The proposition was rejected by the board of RFSU Stockholm. Meanwhile, the board stressed the importance of investigating the need for an expanded antidiscriminationlegislation, and of increasing knowledge and understanding of BDSMF, asexuality and poly/non-monogamous relationships.

Alongside these trends in legislation and institutions, an example of how BDSM is being normalized in Swedish society is the practice of forming traditional Swedish study circles. Study circles have had an obvious and important place in Swedish society. All over Sweden, thousands of circles are conducted on all sorts of subjects. The circles involve regular public education activities that take place in an organized form and often receive state grants for their activities (Törnqvist, 1996). Today, introduction courses and study circles that focus on different areas or practices in BDSM are organized. Using this mainstream form of education is in the Swedish context a significant indication of a shift in status. One informant said: 'My goal was to create an organization in order, with a bank number, a selected board of directors, and a registration number'. By transforming the public perception of frightening and deviant sexuality into study circles, workshops, and associations with boards and bank 
accounts, BDSM is made tolerable and accepted in Swedish society.

Acceptance - for whom and at what cost?

In line with such trends towards normalization and wishes for acceptance, a male masochist reflecting upon Swedish mainstream society's perception of BDSM said: 'I do not want BDSM to be weird. My greatest wish is that those who are young today, those who fantasize when they are fifteen, can see BDSMas different but not deviant'. A somewhat different position is expressed by another male masochist who explains:

I'm not sure that society would gain anything if BDSM becomes more visible. I believe in public education and the idea that one should enlighten people but everyone basic- ally knows what BDSM is today, and we must relate to it, you have to relate to Fifty Shades of Grey, you know what it is. There is television, movies and BDSM is widely known. The question is what BDSM could bring to society if it became more visible. I'm not sure it would add anything, but I think one should work actively until this lifestyle is accepted and people will not be stigmatized.

Such stances contrast with the desire to maintain a free zone for the specially initiated. According to Taylor and Ussher (2001), the relative openness which has been achieved can pose a threat to BDSM culture. For many, the experience of secrecy and exclusivity can be a connecting factor needed to create excitement and enjoyment. The argument that openness leads to tolerance is also not a given. During the autumn of 2016, one of the BDSM communities in Sweden suffered several burglaries in their meeting premises. The motive for the burglaries seemed to be vandalism, and they were classified by the police as hate crimes. At the community's home page at Darkside, the incidents were discussed. One person asked: 'How come that the BDSM culture is attacked now and why has it been spared in the past?' Someone answered that it was because BDSM 'has become more visible, at Pride festivals, in film, media and literature'. The discussion resulted in some members expressing the conclusion that the mainstreaming of BDSM can have counterproductive effects.

Current trends in Sweden with respect to BDSM are, in other words, complex, or even contradictory. To illustrate the progressive changes in different political movements, the concept of the 'wave' is sometimes used as a metaphor. However, Elizabeth Freeman (2010) argues that the metaphor needs to be problematized, since waves also consist of counter- 
currents and backlash where movements can also move backwards. This is evident, not only when it comes to political movements, but also to social attitudes. According to Rydström (2004), every step to liberalize a law seems to be accompanied by some form of constraining measure. He exemplifies this claim with the increasing openness in Sweden during the 20th century regarding practices and spaces associated with 'homosexuality', which was accompanied by a more subtle but increased control of undesirable sexualities. For example, various actions were taken to restrain opportunities, such as trimmed bushes in classic pickup parks in Stockholm, and the removal of changing cabins in bathhouses. Such techniques could, in Foucault's terms, be understood as 'achieving the subjugations of bodies and the control of populations' (1976: 140). Against this background, the following quotation from Heather Love can serve as a good description of the mainstreaming process of BDSM in Sweden:

One may enter the mainstream on the condition that one breaks ties with all those who cannot make it - the non-white and the nonmonogamous, the poor and the gender deviant, the fat, the disabled, the unemployed, the infected, and a host of unmentionable others. (Love, 2007: 10)

Love's analysis of such processes reminds us of the importance of asking who benefits from increased rights and acceptance. If tolerance from the Swedish state can only be achieved by making BDSM part of the 'good sexuality', what will get lost in the process of acceptance?

\section{Normalization and privilege}

Several of the interviewed practitioners expressed that they did not feel that they belong to the mainstreaming process of BDSM. Spade (2011) argues that it is only the more privileged layers of LGBTQ people who can enjoy increased rights from the government, while less privileged people remain without rights - a statement that seems to fit the Swedish BDSM practitioners. Several informants described how BDSM communities can seem exclusionary to people from the working class. Those who can express BDSM using the 'right' concepts, the 'right' language, and belong to the 'right' social settings are at the top of the hierarchy, both outside and inside the BDSM communities. Bauer (2008) questions the stereotype of BDSM people being overwhelmingly highly educated and of middle- to upper-class upbringing, since his sample from the dyke and trans population is diverse with respect to class; 'some interviewees put forth the idea that high-quality BDSM is only for those whom they perceive to be highly educated, "intelligent" or "classy", 
individuals, thus endorsing potentially excluding class-based criteria for member- ship in the community' (2008: 238). Bauer's observation makes it clear that there is a hierarchy in BDSM connected with class. Similarly, in the Swedish context, to become accepted and included in the 'good sexuality', BDSM needs to be considered as a middle-class practice where the 'right' language is used and the practitioners belong to the 'right' social settings. One female submissive expresses her dissatisfaction with such hierarchies, saying:

What is BDSM and who has the right to decide? These are the big questions at Darkside. Should the inside group decide what BDSM is? Do they have these rights? I think too many are forced into how it should be, this and that I must do, and like. There are far too many who want to express their opinion. They believe they know what BDSM is, and that they have the right to tell everyone else.

Drawing on Bourdieu (1989), this could be said to constitute an example of how the middle class, by protecting their interests with symbolic boundary markers, shapes itself as a class, which in turn leads to excluding certain groups of people. Darkside can be seen as what Bourdieu calls 'social space', which 'tends to function as a symbolic space, a space of lifestyles and status groups characterized by different lifestyles' (1989: 20). AccordingtoBourdieu, individualsarepositioned insocial space based on their combinations of capital. Practitioners describe a hierarchy within Darkside, and that there are some people that members are expected to listen to in terms of values and actions. Because of that, one informant ended his account at Darkside:

I put the whole thing down for a while because I was so tired of these cops who told you how to think and how to act, what's right and what's wrong. They sit and point with the whole fist how it should be. Then, in the next breath, they are so very open- minded.

Informal social controls operating within the BDSM community are a way by which the safety of practices and practitioners are ensured (Beckmann, 2009; Weiss, 2011). However, in this given context it appears to have been modes of normative social control in relation to categories of class instead of concerns for safety and communication that shaped the exchange. Such encounters can of course make people feel excluded from the community. While the context of con- sensual BDSM should not be tainted by expressions of categorizations of class and of any normative hierarchies, some practitioners seem to operationalize their 
'cultural capital' (Bourdieu, 1989) which is of course rather a marker of the sado- masochism of everyday (Chancer, 1992). A female switch expresses that she does not fit in at Darkside because 'you have to be in a certain way, to behave in a certain way; they are like jacks-in-office'. Skeggs and Loveday (2012) might say that the informant defends herself from 'the middle class gaze', as they explore how the historical heritage of distinction symbolically marks the working class as the bearer of 'bad culture' and as potentially dangerous and degenerate. A female practitioner, who defines herself as a switch, reflected on the hierarchies in the community, saying:

Maybe, you have an intelligence that is a bit beyond the rest of the population. You feel you need something more, you want to escape the everyday life. To put off weight on your shoulders, to be submissive, and to be taken care of.

It is thus important to note that not everyone benefits equally from increased rights and acceptance. And as we have seen, greater openness in society does not always lead to greater acceptance, but may instead lead to a greater vulnerability for the practitioners and less thrill and excitement.

\section{Conclusion}

Distinguishing between 'good' and 'bad' sexuality not only creates a polarization, but also perpetuates an idea of what is 'normal'. In order to identify what is normal and expected, there must be an antithesis that represents the 'incorrect' sexuality. Which sexual acts are to be seen as good or bad depends on when, where, how and who performs them (Rubin, 2011). Values are not fixed, boundaries shift across time and space. Johannisson writes 'what until the 1700 s was regarded as a sin, became a crime in the $1800 \mathrm{~s}$, and at the turn of the century was classified as a disease' (2010: 128, my translation). With this, Johannisson describes how 'aberrant' sexuality has been used as an instrument of (bio)power. Blaming someone for deviant sexuality has been one of history's most effective weapons, and medical science is closely linked with political intentions, social pressures and norms.

There is no question that mainstream representations of BDSM have increased dramatically, but, as I have shown in this article, to achieve acceptance in Swedish society, a normalization of BDSM is required. This means that acceptance is still based on the premises of mainstream society. Foucault's (1976) ideas of how bio- power shapes both our bodies and our perceptions are undoubtedly relevant to the understanding of how society rewards certain kinds of sexualities above others. 
As we have seen, to become accepted and included in the 'good sexuality', BDSM needs to be normalized, a process that has developed in different ways. For example, by highlighting BDSM as something that engages well-adapted, educated, middle-class people, the practice can be defended against labels of degeneration and perversion. It appears that BDSM can assume a place in Swedish society only by toning down what is still considered perverse and forbidden. Certain stories that go against the Swedish idea of good sex are avoided in this normalization process. The practitioners instead highlight BDSM as associated with study circles, good order, being neat and tidy with a company registration and a bank account. Such attributes confer an appearance of moderation and reason, so that BDSM becomes an accepted and permitted activity. This neatness and tidiness can be seen as a way to defend oneself from the obscure, nasty and dangerous. Only in this way, BDSM can be made 'clean' and thereby accepted and normalized. But the question is, what remains? From what I have seen during several years of field studies in BDSM communities, what makes BDSM desirable for practitioners is the excitement associated with crossing boundaries, to explore the forbidden, and to feel strong emotions of fear, anger, joy and trust. Or as Weiss (2006) put it: 'They want something harder or realer, something that could jolt the viewer out of a complacent, easy, defined, consumptive world. They want some- thing truly outside, disobedient, and undisciplined; something that can break the rules and transgress the bounds; something hard enough to leave marks' (2006: 129). As long as Swedish society continues to privilege the good sexuality manifested in heteronormative, monogamous relationships, which simultaneously oppresses sexual minorities and maintains a line between what is considered 'normal' and 'not normal', it is therefore imperative to critically examine what is considered sexually acceptable and permissible, and what is not in Swedish society. Otherwise the normalization process would appear to ultimately strengthen normative sexuality, rather than challenge it.

\section{Funding}

This work was supported by the Centre for Sexology and Sexuality Studies, Malmo“ University.

\section{Note}

1. Dnr. 2012/180 and 2013/232

\section{References}

Ambler JK, Lee EM, Klement KR, et al. (2016) Consensual BDSM facilitates role-specific altered states of consciousness: A 
preliminary study. Psychology of Consciousness: Theory, Research, and Practice 4(1): 75-91.

Barker M (2013) Gender and BDSM revisited. Reflections on a decade of researching kink communities. Psychology of Women Section Review 15(2): 20-28.

Bauer R (2008) Transgressive and transformative gendered sexual practices and white privileges: The case of the dyke/trans BDSM communities. Women's Studies Quarterly 36(3-4): 233-254.

Bauer R (2014) Queer BDSM Intimacies: Critical Consent and Pushing Boundaries. London: Palgrave Macmillan.

Beckmann A (2001) Deconstructing myths: The social construction of sadomasochism versus subjugated knowledges of practitioners of consensual SM. Journal of Criminal Justice and Popular Culture 8(2): 66-95.

Beckmann A (2009) The Social Construction of Sexuality and Perversion: Deconstructing Sadomasochism. London: Palgrave Macmillan.

Berggren H and Trädgårdh L (2012) Social trust and radical individualism: The paradox at the heart of Nordic capitalism. In: Rembe A and Persson K (eds) The Nordic Way: Equality, Individuality and Social Trust. Stockholm: Swedish Institute, pp. 13-29.

Berggren H and Trädgårdh L (2015) Är svensken människa? Gemenskap och oberoende $i$ det moderna Sverige (Are Swedes human beings? Togetherness and independence in modern Sweden). Stockholm: Norstedts.

Bergman I (director) (1953) Sommaren med Monika (The Summer with Monika) [Motion picture]. Sweden: Cinematograph.

Bourdieu P (1989) Social space and symbolic power. Sociological Theory 7(1): 14-25.

Carlström C (2016) BDSM - Paradoxernas praktiker (BDSM - The practices of paradoxes) $\mathrm{PhD}$ Thesis, Malmö University, Sweden.

Carlström C (2017) Gender equal BDSM practice - a Swedish paradox? Psychology \& Sexuality 8(4): 268-279.

Chancer L (1992) Sadomasochism in Everyday Life: The Dynamics of Power and Powerlessness. New York: Rutgers University Press.

Cisney V and Morar N (2015) Biopower: Foucault and Beyond. Chicago, IL: University of Chicago Press.

Codex (2012) Forskningsetiska principer inom humanistisk samhällsvetenskaplig forskning (Research ethical principles in the arts and social sciences). Stockholm: Swedish Research Council.

Cruz A (2016) The Color of Kink: Black Women, BDSM, and Pornography. New York: New York University Press.

Foucault M (1975) Discipline and Punish: The Birth of the Prison. New 
York: Random House.

Foucault M (1976) The History of Sexuality. Vol. 1. An Introduction. London: Allen Lane.

Foucault M (1980) Two lectures. In: Gordon C (ed) Power/Knowledge. Selected Interviews and Other Writings 1972-1977. New York: Pantheon Books, pp. 78-108.

Foucault M (1997a) Security, territory and population. In: Rabinow P (ed) Ethics. Essential Works of Foucault 1954-1984. London: Penguin, pp. 67-71.

Foucault M (1997b) The birth of biopolitics. In: Rabinow P (ed) Ethics. Essential Works of Foucault 1954-1984. London: Penguin, pp. 7379.

Freeman E (2010) Time Binds: Queer Temporalities, Queer Histories. Durham, NC: Duke University Press.

Herburt K (2009) Sadomasochism i svenska uppslagsverk. En historia om misshandel, våldtäkter och lustmord (Sadomasochism in Swedish encyclopedias. A history of physical abuse, rape and murder for pleasure). Historisk tidsskrift 129(3): 411-428.

Johanisson K (1997) Kroppens tunna skal. Sex essäer om kropp, historia och kultur (The delicate envelope of the body: Six essays on body, history and culture). Stockholm: Norstedts.

Johanisson K (2010) Sexualiteten i historien (Sexuality in history). In: Lundgren PO and Löfgren-Mårtensson L (eds) Sexologi (Sexology). Malmö Liber, pp. 124-131.

Kulick D (2005) Four hundred thousand Swedish perverts. Journal of Lesbian and Gay Studies 11(2): 205-235.

Kulick D and Rydström J (2015) Loneliness and its Opposite. Sex, Disability and the Ethics of Engagement. Durham, NC and London: Duke University Press.

Langdridge D (2011) The time of the sadomasochist: Hunting with(in) the 'tribus'. In: Seidman S, Fischer N and Meeks C (eds) Introducing the New Sexuality Studies. New York: Routledge, pp. 280-287.

Langdridge D and Barker M (2007) Safe, Sane and Consensual: Contemporary Perspectives on Sadomasochism. New York: Palgrave MacMillan.

Lennerhed L (1994) Frihet att njuta: Sexualdebatten $i$ Sverige pa 1960-talet (Freedom to enjoy: Sexual debate in Sweden in the $1960 \mathrm{~s})$. Stockholm: Norstedts.

Levitt E, Moser C and Jamison K (1994) The prevalence and some attributes of females in the sadomasochistic subculture: A second report. Archives of Sexual Behaviour 23(4): 465-473.

Love H (2007) Feeling Backward. Loss and the Politics of Queer 
History. London: Harvard University Press.

Mattsson A (director) (1951) Hon dansade en sommar (One summer of happiness) [Motion picture]. Sweden: Swedish Film Institute.

May T (1993) Social Research. Maidenhead: Open University Press.

Newmahr S (2011) Playing on the Edge. Sadomasochism, Risk and Intimacy. Bloomington: Indiana University Press.

Plante R (2006) Sexual spanking, the self, and the construction of deviance. Journal of Homosexuality 50(2/3): 59-79.

Rehbinder CJ (2016) Dagens Nyheter. Available at: http://www.dn.se/debatt/repliker/det- sexfientliga-samhallet-arproblemet/ (accessed 19 October, 2017).

RFSU Stockholm (2016) Available at: http://www.rfsu.se/PageFiles/27956/Handlingar\% $\quad 20 a^{\circ} \quad 1 / 4$ rsmđie/Motioner\%20och\%20motionssvar_a rsmđe\%202015.pdf?epslanguage sv (accessed 15 October, 2017).

Rubin G (2011) Deviations. Durham, NC and London: Duke University Press.

Rydström J (2004) Från fula gubbar till goda föräldrar: Synen på sexualitet och genus ilagstiftning och debatt 1944-2004 (From nasty old men to good parents: Views on sexu- ality and gender in legislation and debate 19442004). In: Olsson AC and Olsson C (eds) I den akademiska garderoben: Om heterosexuella normer och högre utbildning (In the academic closet: On heterosexual norms and higher education). Stockholm: Atlas, pp. 3765.

Sandnabba K, Santtila P and Nordling N (1999) Sexual behavior and social adaptation among sadomasochistically-oriented males. Journal of Sex Research 36(3): 273-282.

Shainberg S (director/writer/producer) (2002) Secretary [Motion picture]. United States: Lion's Gate Films.

Skeggs B and Loveday V (2012) Struggles for value: Value practices, injustice, judgment, affect and the idea of class. The British Journal of Sociology 63(3): 472-490.

Spade D (2011) Normal Life: Administrative Violence, Critical Trans Politics, and the Limits of Law. New York: South End Press.

Taylor G and Ussher J (2001) Making sense of S\&M: A discourse analytic account.

Sexualities 4(3): 293-314.

Törnqvist I (1996) Oscar Olsson, folkbildaren: I synnerhet hans tankar om universitetens roll $i$ folkbildningsarbetet (Oscar Olsson the educator of the people: In particular his views on the role of universities in popular education). $\mathrm{PhD}$ Thesis, Linköpings University, Sweden.

Ullerstam H (1964) De erotiska minoriteterna (The erotic minorities). 
Uddevalla: Zindermans fölag.

Weinberg T (2006) Sadomasochism and the social sciences: A review of the sociological and social psychological literature. Journal of Homosexuality 50(2): 17-40.

Weinberg T and Magill S (1995) Sadomasochistic themes in mainstream culture. In: Weinberg T (ed) S\&M. Studies in Dominance \& Submission. New York: Prometheus Books, pp. 223-230.

Weiss M (2006) Mainstreaming kink: The politics of BDSM representation in U.S. popular media. Journal of Homosexuality 50(2/3): 103-130.

Weiss M (2011) Techniques of Pleasure: BDSM and the Circuits of Sexuality. Durham, NC: Duke University Press.

Charlotta Carlström has a $\mathrm{PhD}$ in Social Work. Her research focuses on power, gender, body, norms, sexual practices and expressions. Her thesis, BDSM - The practices of paradoxes (2016) is an ethnographic study of BDSM (bondage, discipline/dominance, submission and sadomasochism). Carlström teaches in the master's program in sexology at Malmö University. 